\title{
A teoria da decisão judicial: como os juízes julgam?
}

Judicial decision-making: how do judges decides?

Decisiones judiciales: ¿cómo juzgan los jueces?

\author{
Maria Isabel Rosifini ALVES REZENDE \\ Pós-Graduação Lato Sensu em Direito Processual Civil - $5^{a}$ Edição pela Faculdade de Direito de Ribeirão Preto/SP - USP, 14040-906, Ribeirão Preto-SP, Brasil
}

\section{Resumo}

Como os juízes decidem? A resposta a essa pergunta comporta dois vieses, um seguindo a linha formalista, segundo a qual a atividade de julgar consiste, basicamente, em uma subsunção - isto é, o julgador nada mais é do que um operador de uma grande máquina de silogismo, aplicando a lei abstrata a um caso concreto, de forma mecânica; e outro que observa a linha realista, por meio da qual referida atividade depende, principalmente, de outros elementos, denominados extralegais, por serem alheios ao Direito. O presente ensaio tem como objetivo demonstrar qual movimento se aplica, na prática, ao processo decisório judicial, principalmente no âmbito do Poder Judiciário Brasileiro.

Para tanto, será feita, sucintamente, uma distinção entre as linhas formalista e realista. Após, serão expostos alguns métodos e modelos criados com o escopo de esclarecer como funciona o processo de tomada de decisão, bem como será analisado, brevemente, o princípio da imparcialidade, a fim de que se chegue às considerações finais de maneira genérica.

Descritores: Teoria da Decisão; Decisões Judiciais; Jurisprudência; Julgamento.

\begin{abstract}
How do judges decide? The answer to this question involves two biases, one following the formalist line, according to which the activity of judging consists basically of a subsumption - that is, the judge is nothing more than an operator of a great syllogism machine, applying the abstract law to a concrete case, mechanically; and another that observes the realistic line, whereby certain activity depends mainly on other elements, called extralegals, because they are foreign to the Law. The present essay's purpose is finding which movement applies in practise to judicial decision-making process, especially within the field of the Judiciary. Therefore, a distinction between the formalist and the realist lines will be made briefly, as well as will be analyzed some methods that have been created to try to clarify how judicial decision-making Works in practice, according to Legal Realism. Next, and in conclusion, the Principle of Impartiality will be examined in order to reach the final considerations in a generic way.

Descriptors: Decision Theory; Judicial Decisions; Jurisprudence; Judgment.

\section{Resumen}

¿Cómo deciden los jueces? La respuesta a esta pregunta involucra dos sesgos, uno siguiendo la línea formalista, según el cual la actividad de juzgar consiste básicamente en una subsunción, es decir, el juez no es más que un operador de una gran máquina de silogismo, aplicando La ley abstracta a un caso concreto, mecánicamente; y otro que observa la línea realista, por medio de la cual dicha actividad depende, principalmente, de otros elementos, denominados extralegales, por no estar relacionados con la Ley. El propósito de este ensayo es demostrar qué movimiento se aplica en la práctica a la toma de decisiones judiciales, especialmente en el ámbito del poder judicial brasileño Para este fin, se hará de manera sucinta una distinción entre las líneas formalistas y realistas. Posteriormente, se expondrán algunos métodos y modelos creados con el objetivo de aclarar cómo se expondrá el proceso de toma de decisiones, y se analizará brevemente el principio de imparcialidad, para llegar a las consideraciones finales de manera genérica.
\end{abstract}

Descriptores: Teoría de las Decisiones; Decisiones Judiciales; Jurisprudencia; Juicio.

\section{INTRODUÇÃO}

Quanto do processo de tomada de decisão judicial depende do raciocínio jurídico? Os juízes, após encontrar os fatos relevantes do caso, consultam o ordenamento jurídico para chegar à sua decisão? Ou talvez a equação de que esse processo resulte da combinação "fatos e regras jurídicas" seja apenas uma ilusão? Será que os juízes, na verdade, usam a lei apenas para justificar suas decisões, em vez de usá-la para chegar a elas? Essas são alguns pontos, dentre vários, levantados por Tumonis ${ }^{1}$.

Este ensaio tem por objetivo tecer algumas considerações a respeito da teoria da decisão judicial, de acordo com o realismo jurídico.

Para tanto, inicial e sucintamente, será explicada a teoria da decisão judicial, segundo as teorias do formalismo jurídico e do realismo jurídico. Em seguida, será analisado o processo de tomada de decisão judicial nos moldes do movimento realista.

Após, serão explorados os três modelos principais de comportamento judicial, elaborados por Posner $^{2}$, e qual deles está mais alinhado às formulações do realismo jurídico, assim como o sistema dual, na área da Psicologia Comportamental, o qual também possui grande relação com a abordagem realista.
Ainda, será examinado, brevemente, o princípio da imparcialidade e suas implicações no âmbito do processo decisório e, por fim, serão feitas algumas ponderações genéricas, a fim de que se conclua se o que prevalece, principalmente no âmbito do Poder Judiciário brasileiro, é a aplicação da teoria da decisão judicial formalista ou realista.

\section{REVISÃO DA LITERATURA E DISCUSSÃO}

\section{- Teoria da decisão judicial: aspectos gerais}

Tumonis ${ }^{1}$ introduz ao tema ilustrando a distinção básica entre as duas grandes teorias acerca do processo de tomada de decisão judicial. Essencialmente, para o movimento formalista, julgar cuida-se de uma atividade que se respalda em regras jurídicas e, em suas versões mais extremas, um juiz é visto como um mero operador de uma grande máquina de silogismo. Sob outro ângulo, o resultado de um caso depende de uma subsunção praticada pelo julgador, o qual apenas procura qual lei em abstrato pode ser aplicada a um determinado caso concreto.

Os realistas, por outro lado, entendem que as regras previstas em lei, ou regras formais, não determinam, por si só, os resultados dos casos a serem julgados. Para Frank ${ }^{3}$, o elemento racional na 
lei é uma ilusão, de forma que os resultados judiciais dependem de muitos fatores, tais como a personalidade do juiz, preferências políticas, humor, ideologias, experiências pessoais, dentre outros, sendo, por isso, chamados de elementos extralegais.

Segundo Tumonis ${ }^{1}$ as regras jurídicas não levam à decisão em si mesma, servindo de orientação ao juiz, como um check-up, tendo em vista que, para o autor, os julgadores consultam as leis apenas para verificar se a justificação escolhida para a sua decisão seria aceitável.

Hutcheson ${ }^{4}$ ao narrar sua experiência tanto como advogado quanto como juiz federal, assinala que os juízes primeiro tomam uma decisão - se valem de suas intuições - e só então recorrem às leis ou à jurisprudência para procurar uma justificação. Também assevera que passou a ver que "toda opinião tende a se tornar uma lei" e que "recorrer aos primeiros princípios é, em última análise, o único caminho seguro para a solução da matéria em litígio". Para o autor muitos casos são solucionados pelos julgadores a partir de intuições ou palpites - "hunch", de maneira que os juízes estão abertos a todos os tipos de intuições, aonde quer que eles os levem, diferentemente do que ocorre com o advogado, o qual só busca palpites que sejam favoráveis ao seu cliente $^{4}$.

Simplificadamente, o que se depreende é que todos temos intuições, muitas vezes sem termos ciência de que a tivemos, e, para Hutcheson ${ }^{4}$ é assim que os juízes decidem os seus casos, buscando, em seguida, uma justificativa legal para motivar a sua decisão. Nesse diapasão, "hunch" foi definido pelo autor como "aquele lampejo intuitivo de compreensão que faz o salto conectivo entre a questão e a decisão e, nos pontos mais sombrios para os passos judiciais, lança luz por todo o caminho" ".

Entrementes, outros autores, tais como Richards ${ }^{5}$, entendem que os termos palpite e intuição não podem ser usados de forma intercambiável, conceituando palpite como um produto mental, um resultado consciente de um processo inconsciente e, em virtude de seu uso informal, é substituído, no contexto acadêmico, pela palavra intuição. Neste sentido, o conhecimento intuitivo cuida-se de um processo que requer um conhecimento específico do domínio e de experiência passada, o que nos leva a concluir que, para a autora, não se trata de um processo totalmente inconsciente.

Faz-se mister salientar, neste momento, que este ensaio não possui a finalidade de desvendar como acontece a intuição, isto é, se ela é produto de um processo consciente ou inconsciente, e sim averiguar se, na prática, os juízes embasam suas decisões apenas na previsão legal, no direito posto, ou se fatores alheios ao Direito, provenientes de sua intuição, influenciam o processo decisório.

Voltando à teoria da decisão judicial, em conclusão, a diferença entre os dois movimentos (formalismo jurídico versus realismo jurídico) é que, para os formalistas, a lei e o raciocínio lógico são os pontos centrais que influenciam a tomada de decisão judicial, excluindo a ideia de que tal processo possa decorrer da intuição, de considerações políticas, dentre outras variáveis, enquanto para os realistas, são os elementos extralegais o cerne para a tomada de decisão pelos juízes.

Feitas tais considerações iniciais, este trabalho, para toda a análise a ser construída, partirá, principalmente, do clássico método de julgamento intuitivo, elaborado por Hutcheson ${ }^{4}$, segundo o qual um juiz, automática, intuitiva, e até mesmo inconscientemente, soluciona um litígio, de maneira que suas decisões, sentenças e acórdãos formalmente produzidos não passariam de racionalizações post hoc.

Ademais, acrescente-se, ainda, que, em razão da ausência de consenso no que toca à utilização intercambiável dos termos intuição e palpite, será adotado o uso da palavra intuição para referir-se ao "hunch" explicado por Hutcheson ${ }^{4}$ em sua obra.

\section{- O processo decisório de acordo com a teoria realista}

Holmes, grande realista, que, provavelmente não se consideraria desta forma, se consagrou com a passagem: "Eu sabia que proposições gerais não decidem casos concretos. A decisão dependerá de um julgamento ou intuição mais implícita do que qualquer premissa" no seu voto no caso Lochner vs. New York, em 1905, o qual the deu o mérito de um dos mais importantes predecessores do movimento realista $^{4,6}$.

Para Holmes as mudanças na lei - pelo menos, na lei feita por juízes - não eram consequências da lógica ou de leis pré-existentes, e sim de preferências políticas ou de experiências pessoais dos juízes, que importavam mais.

Neste cenário, oportuno destacar que preferências políticas, em conformidade Posner $^{2}$ não significa que os juízes decidem de modo partidário, e sim para o fim de satisfazer, na maior parte das vezes, e inconscientemente, sua própria ideologia, valores e preconceitos ${ }^{6}$.

Por conseguinte, a colocação de Holmes ${ }^{8}$, no sentido de que "proposições gerais não decidem casos concretos", corrobora a sua posição como realista, consoante à qual regras jurídicas - o Direito - nunca decidirão casos concretos.

É verdade que os realistas não concordavam com muitos aspectos, tanto é que o realismo jurídico é um movimento que surgiu acidentalmente em razão da falta de sistematização na época em que concebido, décadas de 1920 e de 1930 nos Estados Unidos.

Contudo, não obstante a grande divergência existente entre eles, alguns itens lhes eram comuns: 
para a maioria dos realistas, o Direito é indeterminado e o processo de tomada de decisão judicial não se baseia, única e exclusivamente, no ordenamento jurídico - no direito posto.

Neste ínterim, o Direito é indeterminado, porque não se trata de um sistema fechado, rígido, estável ou, como consigna Tumonis ${ }^{1}$, um sistema racional, sem intervalos, completo e quase geométrico, como visto pelo movimento formalista, que deve muito de sua existência à noção de lei como ciência jurídica. Ao contrário, cuida-se de um sistema dinâmico, cujas modificações provêm do contexto social e histórico, dentre outras condições que são aptas a influenciar mudanças sobre a realidade de uma dada sociedade.

O realismo diferencia-se do formalismo, então, em razão deste encarar o Direito como um sistema autoabrangente, segundo o qual todas as soluções necessárias podem ser encontradas dentro do próprio sistema.

Para Frank ${ }^{3}$ os materiais jurídicos tradicionais consistem em apenas uma das classes de estímulos que causam a intuição, havendo muitos outros, "ocultos ou não revelados, frequentemente não considerados nas discussões acerca do caráter ou natureza do direito". Segundo Struchiner e Brando ${ }^{6}$, os trabalhos de Frank $^{3}$ consideram que esses inúmeros e complexos fatores, frequentemente são dependentes dos traços individuais dos juízes, de tal sorte que para conhecer aquilo que produziria os palpites dos juízes, seria necessário conhecer sua personalidade, a qual guiaria a criação judicial do direito, de modo que o direito variaria em estreita relação com a personalidade do juiz que examina determinado caso.

Fica evidente, portanto, que o realismo, por tratar-se de uma teoria descritiva da decisão judicial, sugere que a forma pela qual os juízes decidem e fundamentam as suas decisões na prática difere-se bastante do modo pelo qual se ensina o processo decisório no contexto acadêmico. Para os realistas, há outros elementos, além do sistema jurídico e da jurisprudência, que influenciam o processo decisório judicial.

Por conseguinte, a verdadeira finalidade do realismo jurídico seria encontrar uma previsibilidade, ou seja, entender como funcionam os fatores extralegais, para tentar assimilar como os resultados ou decisões são alcançados pelos julgadores.

Nesta perspectiva, Leiter ${ }^{9}$ entende que existe um núcleo duro do realismo compartilhado entre todos os realistas, formado pela indeterminação do Direito e da racionalidade jurídica, o que significa dizer que o Direito não é o único fator levado em consideração para uma decisão judicial, existindo outros além dele.

Este autor fragmentou o realismo em duas categorias, ou linhas de pensamento: a idiossincrática e a sociológica. Pela primeira, fatores internos aos juízes determinavam a sua decisão e, como cada julgador possui uma personalidade e uma forma de pensar distintas, era impossível tentar encontrar qualquer previsibilidade no resultado. Esta categoria foi sustentada por Frank ${ }^{3}$ e Hutcheson ${ }^{4}$, ao sugerirem que o juiz decide a partir de uma intuição sobre o que constituiria um resultado justo para determinado caso concreto. Em contrapartida, de acordo com a linha sociológica, são os fatores externos que influenciam as decisões, contribuindo para a criação de um padrão previsível de decisões judiciais.

Levando em consideração todas essas concepções formuladas pelos realistas, no próximo item serão explicados, sinteticamente, os modelos de comportamento judicial traçados por Posner $^{2}$ e a relação da teoria atitudinal com o processo de tomada de decisão pelos juízes, em conformidade com o realismo jurídico.

- Os modelos de comportamento judicial elaborados por Richard Posner

Foram concebidas diversas teorias as quais procuram definir os fatores determinantes do comportamento judicial. Nesta toada, há três modelos, desenvolvidos por Posner $^{2}$, que se destacam: jurídico, atitudinal e estratégico.

A teoria jurídica está associada a uma abordagem normativa, mediante a qual o comportamento judicial restringe-se ao Direito. Alguns estudiosos entendem que, dentro deste modelo, existem duas perspectivas: uma normativa e uma positivista.

Sob a perspectiva normativa, as decisões judiciais são tomadas a partir de apenas dois elementos: fatos e ordenamento jurídico, não havendo espaço para visões pessoais do juiz ou a influência de fatores externos. Já sob a visão positivista, os juízes podem decidir de acordo com a sua própria ideologia ou satisfazendo a pressão de atores políticos, mas levando em consideração o direito posto. Para Friedman ${ }^{10}$, enquanto os positivistas discutem o comportamento dos juízes os normativos consideram como os juízes deveriam se comportar.

Pela teoria atitudinal, os juízes decidem de acordo com as suas preferências político-ideológicas, isto é, eles tendem a decidir politicamente. Em contrapartida, a teoria estratégica vai além e sugere que o julgador, além de levar em consideração a sua preferência política, adotará determinadas estratégias, decidindo de maneira a alcançar os seus objetivos.

Ou seja, o magistrado também irá considerar, inicialmente, a probabilidade de sua decisão ser revertida em segunda instância ou nos Tribunais superiores, sua reputação e prestígio, o seu desejo de ser promovido, agindo com a finalidade de assegurar um resultado mais próximo ao por ele preferido, segundo seus valores, objetivos e visão de mundo ${ }^{11}$. 
Segundo Ferreira ${ }^{12}$, o modelo jurídico é considerado o mais tradicional e favorito dos juristas, é o modelo ensinado nos cursos de graduação de Direito. Para o autor, o que determina a decisão de um juiz é a lei, de modo que as regras jurídicas e a política não se misturam. Ainda que a lei seja obscura, o processo decisório continua vinculado a determinadas regras.

A teoria atitudinal assinala que o juiz decide de acordo com a sua preferência político-ideológica. $\mathrm{Na}$ literatura norte-americana, as preferências políticas associadas ao partidarismo são classificadas como liberal ou conservadora, estando os liberais associados ao Partido Democrata (esquerda) e os conservadores, ao Partido Republicano (direita). Cumpre relembrar que os juízes federais, nos Estados Unidos, em todos os níveis, são indicados pelo Presidente da República.

Cross ${ }^{13}$ elucida que os juízes agem, de acordo com esse modelo, como qualquer outro funcionário do governo, buscando proteger suas ideias de justiça na sociedade por meio de suas decisões, sem qualquer restrição neste processo. Neste sentido, Hughes $^{14}$, ex-presidente da Suprema Corte Americana, em um discurso perante a Câmera de Comércio, em Elmira, Nova York, afirmou que embora todos estejam sob a Constituição, a Constituição seria o que o juiz diz que ela é, enquanto o poder judicial seria a salvaguarda da liberdade e da propriedade nos termos da Constituição.

Dentre esses três modelos de comportamento judicial mais utilizado, aquele que mais se aproxima da proposta elaborada pelo realismo jurídico, e também por outras áreas de conhecimento (Ciência Política, Economia e Psicologia) é a teoria atitudinal.

Parafraseando Ribeiro e Arguelhes ${ }^{15}$ o modelo atitudinal aproveita a ideia realista de que o Direito não se trata de um sistema lógico, autônomo, estático, fechado, e sim como algo indeterminado e variável de acordo com as mudanças sociais. Para os autores, as interpretações dadas pelos juízes aos conceitos, regras e princípios vagos e indeterminados é o que permite a adaptação do Direito à dinâmica da vida social. Prosseguem destacando que nessa concepção, ao interpretar o Direito o juiz também o cria.

Segal e Spaeth $^{16}$ incorporam, além dessa proposta de criação do direito do realismo jurídico, a suposição de que a criação do direito por parte dos juízes tem causas extralegais, em contraste com a ideia de que o desenvolvimento do direito nas decisões judiciais ocorre a partir de elementos e argumentos internos ao próprio sistema jurídico (precedentes, leis, texto constitucional, etc.). Nessa perspectiva, os argumentos legais que preenchem e sustentam as interpretações dos juízes são vistos como meras racionalizações.

Pelo modelo atitudinal, portanto, o que permite aos juízes criarem e recriarem o Direito é o fato de ser ele indeterminado e variável, consoante à proposta desenvolvida pelo realismo jurídico, e, ao agirem desta forma, eles buscam maximizar suas próprias preferências políticas, de maneira que os argumentos legais são usados como mera justificativa de sua decisão. Cabe ressaltar que, segundo Ribeiro e Arguelhes ${ }^{15}$ a maximização das preferências sobre os objetivos políticos sofre limitação do contexto institucional (regras do jogo) e da situação da decisão sobre o mérito.

Em conclusão, pela teoria atitudinal, a tomada de decisão não se baseia única e exclusivamente no direito posto - rule of law, o qual se caracteriza como um dos fatores determinantes e também limitantes da decisão, mas somado a outros elementos externos ao Direito, supramencionados.

- O sistema dual

$\mathrm{Na}$ Psicologia, disciplina intimamente ligada ao processo decisório, sob o prisma do movimento realista, Kahneman e Frederick $^{17}$, inspirados no modelo elaborado por Stanovich e West ${ }^{18}$, descreveram as formas de pensar por meio de uma metáfora de dois agentes autônomos: Sistema 1 (S1) e Sistema 2 (S2).

O S1 é intuitivo, impulsivo, rápido, automático, inconsciente, com pouco ou nenhum esforço e exige pouca energia para o seu funcionamento. É neste sistema em que residem os vieses cognitivos ${ }^{17}$. S1 permitiria tirar conclusões precipitadas e pouco embasadas por evidências ${ }^{19}$. O S2, por outro lado, é cauteloso, lento, preguiçoso, consciente e demanda um gasto bem maior de energia para o seu funcionamento ${ }^{17}$.

O Sistema 1 gera, continuamente, sugestões ao Sistema 2, tais como impressões, intuições, intenções e sentimentos. Se transferidas ao S2, transformar-se-ão em crenças e ações voluntárias. Entretanto, o Sistema 2 apresenta alguma capacidade de mudar a maneira pela qual o Sistema 1 funciona, programando as funções normalmente automáticas de atenção e memória ${ }^{17}$.

A tarefa principal do S2, na verdade, é dominar e controlar os impulsos e os erros praticados pelo S1. Quando este funciona com dificuldade, ele recorre ao $\mathrm{S} 2$, para que ele faça um processamento mais detalhado e específico, a fim de proporcionar uma solução ao problema pontualmente surgido ${ }^{17}$.

Guthrie et al. ${ }^{20}$ propuseram um modelo de decisão judicial designado "formalismo realista" ou "supraintuitivo", que consiste na mistura entre formalismo e realismo. Neste cenário, Costa ${ }^{20}$ explica que o modelo realista reconhece a importância da regra de pressentimento judicial, enquanto o modelo formalista reconhece a importância da deliberação como forma de restringir a inevitável e frequentemente indesejável influência da intuição. Portanto, caberia ao processo deliberativo, ligado ao 
Sistema 2, a missão de verificar os acertos e desacertos do processo intuitivo, ligado ao Sistema 1. $\mathrm{O}$ autor destaca ainda que enquanto o Sistema 2, lento e preguiçoso, exige esforço, motivação, concentração e execução de regras de aprendizado, o Sistema 1 é automático, rápido, se desenvolve espontaneamente e sem esforço e não requer ou consome atenção. Assim, segundo o autor, o modelo realista não enxergaria o juiz como o decisor puramente dedutivo dos formalistas, nem como o racionalizador intuitivo dos primeiros realistas, mas como uma pessoa comum com tendência a ser levada por intuições, embora seja capaz de superá-las por meio de pensamento complexo e deliberativo ${ }^{20}$.

Para Richards ${ }^{5}$ o S1 é usado na maioria das tarefas diárias, quando as pessoas lidam com ambientes familiares e operações mentais, e pode ser melhor compreendido ao ser relacionado com o S2, responsável pelo autocontrole. O Sistema 2, por exemplo, controla nossos impulsos quando os consideramos inadequados em uma dada situação, assim como pode programar a memória para obedecer a uma instrução em substituição às respostas habituais. Simplificadamente, o S2 é o lado duvidoso, enquanto o S1 é o lado que acredita. Assim, se o S2 está ocupado ou cansado, o S1 é persuadido de forma muito mais fácil. Para a autora as intuições e os palpites são componentes naturais e essenciais do processo decisório judicial, enquanto o raciocínio legal equivale a pensar de forma lenta (Sistema 2) e desempenha um importante papel na tomada de decisão, pois o pensamento lento é essencial na criação de padrões, quando eles não existem, além de ter grande importância depois que o palpite ocorreu, no posterior processo de justificação, tal como ocorre aos legisladores e filósofos

Nos Estados Unidos, que enraizaram os sistemas jurídicos com aspirações de lógica e de perfeição, tratando a intuição como um elemento irracional, a maioria dos juízes sente constrangimento ao reconhecer as intuições como parte de seu trabalho, preferindo encobri-las e compensá-las, escrevendo suas decisões como os teóricos legais e os legisladores fariam em seu lugar 5 .

Nos moldes da tese sustentada pelos realistas, principalmente por Hutcheson ${ }^{4}$ em seu método de julgamento intuitivo, e Leiter ${ }^{9}$, na divisão do realismo em categorias, o ordenamento jurídico é um fator que compõe a decisão, mas não é o ponto central, visto que elementos alheios ao Direito influenciam, na prática, o processo decisório judicial.

Importante reforçar que a finalidade deste ensaio não é explorar se o processo decisório, a partir da intuição, é consciente ou inconsciente.

Por enquanto, foram feitas, genericamente, algumas considerações sobre a tomada de decisão judicial, sob a visão do realismo jurídico, sendo importante demonstrar a relação deste movimento com a área da Psicologia, sobretudo para corroborar o fato de que se todos nós temos intuições - às vezes, sem "ter consciência" de que as tivemos, do que as originou - oriundas de experiências de vida, de formas de pensar, da própria personalidade, de preferências político-ideológicas, dentre outros elementos, e que estão aptas a influenciar o processo decisório no geral, como é possível afirmar que o "hunch" está desvinculado do processo de tomada de decisão no âmbito judicial? Em outras palavras, como é possível assegurar que a tomada de decisão pelos juízes, que também são seres humanos e, por isso mesmo, cometem falhas, restringe-se apenas ao Direito?

\section{- Princípio da imparcialidade}

Sucintamente, consiste o princípio da imparcialidade em um pressuposto de validade do processo, por meio do qual o juiz não se interessa pela causa nem toma partido por quem quer que seja. É visto como um dever do juiz perante o qual se desenrola o processo. $\operatorname{Costa}^{20}$ assinala que a imparcialidade é garantia de que os juízes não irão distorcer o conteúdo da lei para benefício próprio, político, altruístico ou à parte do processo.

O juiz, como qualquer outro ser humano, apresenta uma forma particular de pensamento e personalidade, de modo que a imparcialidade deve ser entendida de forma aproximada ou relativizada.

$\mathrm{Na}$ verdade, o que se verifica, de fato, nos processos é a denominada equidistância, conforme a qual o magistrado se encontra à mesma distância tanto de uma parte quanto de outra, sem um vínculo direto com qualquer uma delas.

Todavia, cumpre salientar que, sendo o caso de alegação de impedimento ou suspeição, hipóteses nas quais o juiz possui alguma relação direta com uma das partes, o Código de Processo Civil, em seus artigos 144 a 148, estabelece um procedimento para o seu processamento, a fim de afastá-lo dessa situação em concreto, justamente para preservar, o máximo possível, o princípio da imparcialidade.

Nesse diapasão, qual a relação do princípio da imparcialidade com a teoria da decisão judicial, segundo o movimento realista? Partindo da premissa de que os juízes decidem segundo a sua intuição ou "hunch" e, depois, buscam na lei uma justificação para a sua decisão, o que se conclui é que, na prática, a imparcialidade não existe.

Ora, se os magistrados se valem de suas preferências político-ideológicas, valores, noção pessoal de justiça e de outros elementos, intuitivamente, no processo decisório, como pode ser aplicada a imparcialidade? Posner $^{2}$ considera que, além do direito, a decisão de um julgador se calca em elementos externos: a opinião pública, em se tratando de um caso sujeito à influência midiática; a aceitação da decisão pelos colegas dentro da instituição; a sua experiência pessoal; a possibilidade de promoção e 
de reversão da decisão em segunda instância ou nos Tribunais Superiores; o próprio ordenamento jurídico.

Por conseguinte, é possível certificar que todo e qualquer processo decisório, principalmente se estiver sujeito à influência da mídia, ampara-se exclusivamente no ordenamento jurídico, seguindo a teoria jurídica do comportamento judicial - em atenção ao princípio da imparcialidade, inclusive, ou se baseia nas preferências políticas do julgador, conforme conceituado por Posner $^{2}$, nos moldes do modelo atitudinal?

\section{CONSIDERAÇÕES FINAIS}

De acordo com as considerações expostas ao longo deste ensaio, resta claro que o ordenamento jurídico é um dos elementos que influenciam na tomada de decisão, mas não o único, de forma que os juízes se valem de sua intuição para a resolução dos casos.

Partindo da proposição de que os juízes, como seres humanos, são detentores de um sistema mental S1/S2 funcional, isso significa que estão propensos a pensar rapidamente - de forma rápida, intuitiva, inconsciente - ao lidar com situações e tarefas familiares, voltando ao pensamento lento quando novas situações problemáticas - isto é, não corriqueiras - aparecerem. O Sistema 1 (S1), intuitivo, é ativado quando o juiz, ao reconhecer em um novo caso características que o tornam semelhante a um antigo aplica intuitivamente, a mesma solução. Por conseguinte, os magistrados, ao se depararem com casos com os quais não possuem habitualidade ou experiência, porquanto não tenham solucionado anteriormente situação análoga, tendem a utilizar o seu Sistema 2 (S2), consciente e lento, que lhes custa muita energia mental e requer atenção.

Destarte, ao menos que em parte a tese sustentada pela maioria dos realistas seja confirmada, um julgador não decide calcado exclusivamente no direito, havendo outros fatores externos que influenciam a sua decisão, tais como sua preferência político-ideológica, opinião pública, em se tratando de um caso sujeito à influência midiática, aceitação da decisão pelos colegas dentro da instituição, experiência pessoal, possibilidade de promoção e de reversão da decisão em segunda instância ou nos Tribunais Superiores, e por fim, o próprio ordenamento jurídico.

Trazendo tais considerações ao âmbito do Poder Judiciário brasileiro, genericamente, o que se conclui neste trabalho é que, de fato, a teoria realista é a que melhor se enquadra na realidade brasileira, tendo em vista que há diversos elementos extrajurídicos de peso que influenciam o processo decisório, além do próprio sistema jurídico, e isso é verificado, com mais facilidade, nos processos em que figuram como parte agentes políticos, bem como naqueles casos dotados de notória repercussão social, após sua divulgação pela mídia.

Assim, o que se pretendeu apresentar, neste ensaio, é que os fatores extralegais, muitos, inclusive, provavelmente desconhecidos pelos estudiosos do Direito e de outras áreas de conhecimento intimamente ligadas a essa vertente de pesquisa, somados ao direito posto, influenciam as decisões dos juízes, ao longo de um processo, nos moldes das proposições elaboradas pelos realistas.

Contudo, o que ainda não se pode afirmar de forma categórica é qual o peso exato de influência de cada um destes elementos sobre a tomada de decisão.

\section{REFERÊNCIAS}

1. Tumonis V. Legal Realism \& Judicial DecisionMaking. Jurisprudence. 2012;19(4):1361-82.

2. Posner RA. How judges think. London: Harvard University Press; 2008.

3. Frank J. Courts on trial: mith and reality in american justice. Princeton: Princeton University Press; 1973.

4. Hutcheson Jr JC. Judgment Intuitive: The Function of the "Hunch" in Judicial Decision. 1929 , p. 274-88.

5. Richards D. When judges have a hunch - intuition and experience in judicial decision-making. ARSP. 2016;102(2):245-60.

6. Struchiner N, Brando MS. Como os juízes decidem os casos difíceis do direito? Novas Fronteiras da Teoria do Direito: da filosofia moral à psicologia experimental. Rio de Janeiro: PoD/PUC Rio; 2013.

7. Cestari R, Nojiri S. Intepretações históricas e teóricas do Realismo Jurídico. XXIV Encontro Nacional do CONPEDI - UFS, Teorias da Decisão e Realismo Jurídico; 2015. p. 142-66.

8. Holmes Jr OW. Lochner v. New York, 198 U.S. 45, 76. 1905.

9. Leiter B. Rethinking legal realism: toward a naturalized jurisprudence. Tex L Rev. 1997; 76(2):267-315.

10.Friedman B. The politics of judicial review. Tex L Rev. 2005;84(2):257-337.

11. Horta RL, Costa AA. Das Teorias da Interpretação à Teoria da Decisão: por uma perspectiva realista acerca das influências e constrangimentos sobre a atividade judicial. R Opin Jur. 2017;15(20):271-97.

12.Ferreira PFAN. Como decidem os ministros do STF: pontos ideais e dimensões de preferências [dissertação]. Brasília: Universidade de Brasília; 2013.

13.Cross FB. Decisionmaking in the U.S. Circuit Courts of Appeals. Cal L Rev. 2003;91(6):1457-515.

14.Hughes CE. Addresses and papers of Charles Evans Hughes,Governor of New York,1906-1908. New York: GP Putnam's Sons; 1908. 
15.Ribeiro LM, Arguelhes DW. Preferências, Estratégias e Motivações: Pressupostos institucionais de teorias sobre comportamento judicial e sua transposição para o caso brasileiro, Rev Direito e Prax. 2013;4(7):85-121.

16. Segal JA, Spaeth HJ. The Supreme Court and the Attitudinal Model. Cambridge: Cambridge University Press; 1993.

17. Kahneman D, Frederick S. A model of heuristic judgment. The Cambridge handbook of thinking and reasoning. Cambridge: Cambridge University Press; 2005.

18. Stanovich KE, West RF. Individual differences in reasoning: implications for the rationality debate? Heuristics and biases: the psychology of intuitive judgment. Gilovich T, Griffin D, Kahneman D (org). New York: Cambridge University Press; 2002.

19. Costa EJF. Levando a imparcialidade a sério: proposta de um modelo interseccional entre direito processual, economia e psicologia [tese]. São Paulo:Pontifícia Universidade Católica; 2016.

20.Guthrie C, Rachlinski JJ, Wistrich AJ. Blinking on the bench: how judges decide cases. Cornell $\mathrm{L}$ Rev. 2007; 93(1):1-43.

\section{CONFLITO DE INTERESSES}

A autora declara não haver conflitos de interesse.

AUTOR PARA CORRESPONDENCIA

Maria Isabel Rosifini Alves Rezende

mariaisabel.rezende@hotmail.com

Submetido em 05/03/2019

Aceito em 27/03/2019 